\title{
Research on College Physics Experiment Teaching Based on Flipped Classroom Mode
}

\author{
Fengjin Xia, Shuai Ma*, Guoquan Zhu, Bing Feng, Jing Liu, Wunan Li and Guanghai \\ Guo
}

School of Mathematics \& Physics, Qingdao University of Science \& Technology, Qingdao 266061, P. R. China *Corresponding author. Email: shuai.ma@qust.edu.cn

\begin{abstract}
Physics experiment is a basic course in the colleges of science and technology. This course can cultivate students' ability by using experimental methods to discover, analyse and solve problems. At the same time, they can cultivate students' rigorous scientific thinking and innovative ability. In order to improve the efficiency of classroom teaching, promote their independent learning ability, we have introduced the flipped classroom concept into the teaching process, and carried out a deep reform of the original teaching mode. Herein, we discussed the existing problems of the current college physics experiment teaching mode, and the application of the flipped classroom mode in teaching process.
\end{abstract}

Keywords: College physics experiment teaching, Flipped classroom, Teaching reform, Xuexitong.

\section{TRADITIONAL TEACHING MODE}

In recent years, many researchers have explored the teaching mode of physics experiments in universities. These researches have achieved some results, but there are still some problems and shortcomings $[1,2]$.

\subsection{Teachers Lack of New Teaching Concept}

At present, many teachers still stay in the past teaching concept. They have not understanding the meaning of "Double First-Class" construction. They lack the new teaching technologies and methods. The new concept is not updated in the experimental classroom teaching. Experimental teaching has principles, scenarios, and tools. It should be fresh and fun; however, backward teaching style have led to experimental teaching become boring, difficult to realize the goal of the education. Students are actively involved in experimental classroom teaching. Therefore, physics experiment teaching can't achieve the relevant educational objectives, and can't achieve the cultivation of innovative ability. Then, it is difficult to achieve the talent training goal of "Double First-Class" construction.

\subsection{The Classroom Lack of Interaction}

In the teaching process, the communication and discussion between teacher and students are shortage, and it is difficult to consider the individualization and differentiation of students. In order to complete the teaching task in the limited classroom teaching time, it is difficult for teachers to think out the personality and differences of each student. It is difficult to solve each student's problems in the classroom [3].

\subsection{The Assessment Method is Outdated}

Most of the assessment methods are divided into two categories. The first category is based on the usual classroom experiment report, through preview, operation and results processing, a comprehensive evaluation of students' understanding and mastery of an experimental project. At the end of the semester, the total score for all projects is the student's final grade. The second category is based on the examination. Both methods of assessment were significantly flawed, leading students to mistakenly believe that better results could be achieved by the well written experiment reports or the well answered test papers. They neglect the nature of physics experiment as a practical course, which leads students to pay more attention to 
completing the experimental report or reading theoretical knowledge, and weakens the cultivation of practical skills [4].

\section{FLIPPED CLASSROOM TEACHING MODE}

Flipped classrooms originated in the United States, created by two chemistry teachers, Bergman and Sams [5]. This mode transforms traditional classroom lectures into a form of pre-class video viewing, communication, and discussion in the classroom by using modern teaching methods and network resources [6]. In the flipped classroom, students play their own subjective initiative, change the past teachers and student's monotonous role. Teachers have changed from classroom leaders to student knowledge guides, and students have become real learning topics. In the flipped classroom, teacher and students communicate freely through the network platform to find and solve students' problems [7].

In order to solve the problems existing in the traditional teaching mode, we introduce the new flipped-type classroom teaching mode into the physics experiment teaching [8]. The new teaching mode take full account of the individualization and differentiation of different students, and transform the teacher's face-to-face teaching into a student-led active learning mode through micro-classroom, mobile application, or other resources. This mode cultivates students' independent learning ability, independent thinking, and cooperative exploration.

\subsection{The Preparation of Flipped Classroom}

We have established a flipped classroom teaching model based on mobile APP "Xuexitong". As a mobile teaching tool, "Xuexitong" has the following outstanding advantages over similar products: (1) Rich in resources. The "Xuexitong" platform including periodicals, books, topics, newspapers, lectures, and so on. (2) Data synchronization. The learning data on mobile APP and computer-side network teaching platform synchronization, including the construction of curriculum data, subject interaction, learning data, etc. (3) Communication functions. Sign in with the organization's account, so you can communicate online between different universities. In addition, the complete teaching module is one of the reasons why many teachers choose the "Xuexitong", including material distribution, class group chatting, classroom interaction, login voting, and so on, even the mainstream live broadcast function is supported by arranging micro-classroom video recording according to the teaching content, making teaching courseware and uploading it to the "Xuexitong" platform. In the traditional teaching mode, students prepare experiments mainly by completing preview reports. When they encounter problems, they can only consult the textbooks themselves. The familiarity with the experimental program and the understanding of the instrument structure are shortage, resulting in poor preview effect. Under the new mode, prep is no longer the dullness of students completing pre-school reports, but is replaced by resources such as vivid micro-classroom videos and MOOC materials.

In the new mode, students complete the experimental project through APP and other related teaching resources, making the learning process of the college physics experiment more interesting, active, and relevant. According to their own learning plan, students choose the right time to $\log$ on to the APP to watch videos, which make better use of their time.

\subsection{The Process of Flipped Classroom}

In the traditional teaching mode, teacher need to spend a lot of time in the classroom to explain the principles of experiments, procedures, instruments, preventive measures, etc., both time-consuming and laborious. At the same time, students do not have enough time to operate the equipment [9].

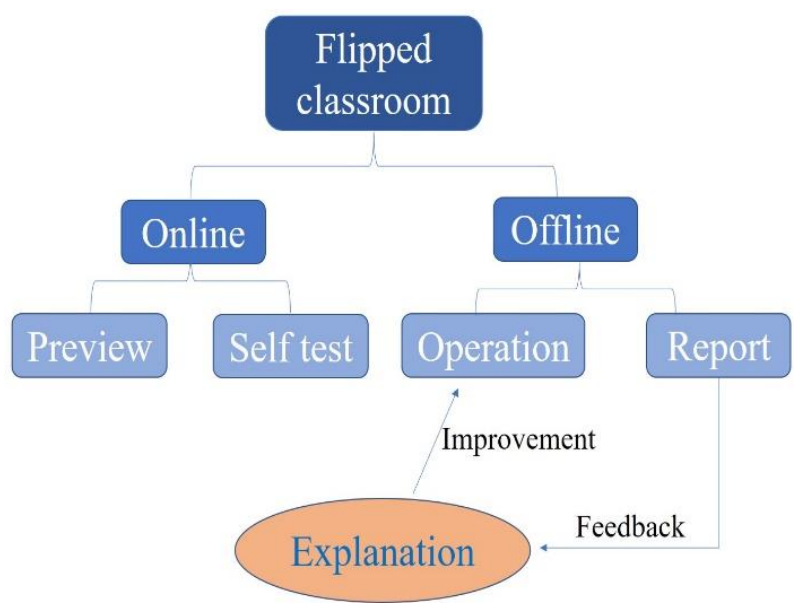

Figure 1. The schematic diagram of flipped classroom

By using flipped classroom teaching mode as seen in Figure 1, students can preview online, and teachers can no longer introduce experimental programs [10]. Under the new mode, more attention is paid to guiding students to internalize their knowledge through the exchange and discussion between teachers and students in the classroom. We were prepared to set up a combination of questions (question library) for the important points of each experiment. Teachers can randomly select related questions from the question library for classroom discussion, and make full use of teaching equipment resources to project APP-related modules onto the screen. Teacher-student interaction replaces the original teacher's explanation. This will promote the students to participate the discussion. During the discussion, 
students can interact and reappear on the big screen. in teacher-student exchanges, teacher can learn about the class's prep, and students can learn from each other's answers. So, this teaching process is more effective. After classroom discussion and communication, students have mastered the difficulties of experiments and instrument adjustment precautions and techniques. More importantly, this mode changed the monotony of the role relationship between teachers and students. Teachers change to student knowledge-led from classroom leadership. The students really become the main body of the classroom.

\subsection{After-school Evaluation and Reflection}

Based on the experiment, students analyze the results of the experiment and prepare the reports, and take note of the problems they encounter in class. The project expands in the form of analytical thinking problems. After-school feedback evaluation is very important for flipping the classroom. Through this link, teachers can understand the students' mastery of the curriculum and the teaching effect of the classroom. Under the new model, we realize feedback evaluation through the following three aspects: (1) Review the experimental report, focus on correcting data processing and analytical thinking problems: (2) Teachers use the questionnaires in the APP and student feedback module for online platform data statistics: (3) The flipped classroom and information technology combined, the establishment of WeChat auxiliary teaching group. Through the above methods, teachers will examine the teaching effect of the new mode, participate in discussions, experimental interests, and optimize the teaching plan.

\section{THE TEACHING EFFECT OF THE NEW MODE}

Under the new teaching mode, teacher is no longer the only source of knowledge dissemination. Knowledge transfer is placed outside the classroom. Students learn independently by using materials online. Compared with traditional teaching, teachers have prepared abundant and specific resources, including PPT, video, and so on, in the form of flipped classroom, which shorten the time of experimental preparatory and operation time. For Young's module experiments, the preparation time was reduced from 60 minutes to 20 minutes. Most of the students in the class were able to complete the experiment ahead of schedule, and the failure to complete the experiment during the prescribed class hours was greatly reduced. More importantly, by using the flipped classroom mode, the teacher's lecture section was replaced by questions and answers. The classroom atmosphere is more active, Because of more questions were asked in classroom, the learning effect is better than before.

\section{CONCLUSIONS}

Under the new situation, the original teaching mode has been reformed in depth, so that the flipped classroom and experimental teaching can be effectively combined, and the teaching effect is optimized. Flipping the classroom can promote the personalized development of students and speed up the construction of educational informationization in China. Flipping the teaching mode of classroom will become a new trend of educational reform.

\section{AUTHORS' CONTRIBUTIONS}

All the authors discussed and commented on this study. Fengjin Xia wrote the manuscript.

\section{ACKNOWLEDGMENTS}

This work was supported by the educational reform project of Qingdao University of Science \& Technology.

\section{REFERENCES}

[1] J. Wang, Research on the reform of college physics experiment teaching based on the combination of online and offline., Physics and Engineering, 30 (2020) 26-31.

[2] X.Z.W. X. J. Pu, J. J. Yang, S. M. Wang, Z. H. Fang, Oline teaching practice of home-base physics experiment in cupt mode., Physics and Engineering, 31 (2021) 12-18.

[3] D. Wang, Reflections on the Teaching Reform of College Physics Experiment in the Background of Double Top Constructions, Physical Experiment of College, 31 (2018) 120-122.

[4] J.M.L. B. Liu, Y. L. Yin, D, Li, Research on virtual simulation experiment assisting physics experiment teaching., Physics Experimentation, 2020 (2020) 40-46.

[5] G. Akçayır, M. Akçayır, The flipped classroom: A review of its advantages and challenges, Computers \& Education, 126 (2018) 334-345.

[6] N. Zhang, Discussion on flipped classroom teaching mode based on MOOC environment., Modern Communication, 2 (2017) 169-170.

[7] L.R. Murillo-Zamorano, J.Á. López Sánchez, A.L. Godoy-Caballero, How the flipped classroom affects knowledge, skills, and engagement in higher education: Effects on students' satisfaction, Computers \& Education, 141 (2019) 103608.

[8] P. Strelan, A. Osborn, E. Palmer, The flipped classroom: A meta-analysis of effects on student 
performance across disciplines and education levels, Educational Research Review, 30 (2020) 100314.

[9] X.P.Z. C. Y. Gao, Organization and design of flipped classroom in unversity physics experiment,
Journal of Lanzhou University of Arts and Science (Narural Sciences), 33 (2019) 116-121.

[10] I.T. Awidi, M. Paynter, The impact of a flipped classroom approach on student learning experience, Computers \& Education, 128 (2019) 269-283. 